\title{
A new insight into foaming mechanisms in injection molding via a novel visualization mold
}

\author{
V. Shaayegan, L. H. Mark, A. Tabatabaei, C. B. Park* \\ Microcellular Plastics Manufacturing Laboratory, Department of Mechanical and Industrial Engineering, University of \\ Toronto, M5S 3G8, Toronto, Ontario, Canada
}

Received 21 October 2015; accepted in revised form 27 December 2015

\begin{abstract}
The complex mechanisms of bubble nucleation and dynamics in foam injection molding have not been uncovered despite many previous efforts due to the non-steady stop-and-flow nature of injection molding and the non-uniform temperature and pressure distributions in the mold. To this end, a new visualization mold was designed and manufactured for the direct observation of bubble nucleation and growth/collapse in foam injection molding. A reflective prism was incorporated into the stationary part of the injection mold with which the nucleation and growth behaviors of bubbles were successfully observed. The mechanisms of bubble nucleation in low- and high-pressure foam injection molding, with and without the application of gas-counter pressure, was investigated. We identified how the inherently non-uniform cell structure is developed in low-pressure foam injection molding with gate-nucleated bubbles, and when and how cell nucleation occurs in high-pressure foam injection molding with a more uniform pressure drop.
\end{abstract}

Keywords: processing technologies, nucleation mechanism, foam injection molding, in-situ visualization, polystyrene

\section{Introduction}

Foam injection molding (FIM) is an encouraging manufacturing method, owing to its capability to produce lightweight products by using less material and consuming less energy at fast production rates. In addition, recent studies have demonstrated that the formation of the cellular structure in FIM can improve mechanical and physical properties of the foamed parts [1-3]. However, most of the underlying mechanism(s), contributing to the cellular structure development, are not fully understood in this technology. The absence of a comprehensive understanding of bubble nucleation mechanisms, bubble dynamics, and mutual interactions of growing bubbles and fillers not only limits any structural improvement to empirical trial and errors, also hinders new material designs for enhancement of specific properties in products.
Although extensive research has been conducted to interpret the foaming phenomena in FIM, characterization was performed on the final structure after the samples were stabilized [4]. Therefore, the foaming phenomena were not tracked during the process. Additionally, most of hypotheses or theoretical simulations were not experimentally verified $[5,6]$. In this context, the in-situ observation of foaming phenomena drew significant attention amongst researchers [7-10]. Villamizar and Han [7] designed a rectangular visualization mold with transparent quartz walls to investigate the bubbles' dynamics in conventional structural FIM. Mahmoodi et al. [8] used a visualization setup in which one side of the mold cavity was replaced with a multi-layer glass block in the moving part of the mold. They conducted fullshot FIM experiments using polystyrene (PS)/carbon dioxide $\left(\mathrm{CO}_{2}\right)$ system to visualize cell growth and

\footnotetext{
${ }^{*}$ Corresponding author, e-mail: park@mie.utoronto.ca

(C) BME-PT
} 
collapse during non-isothermal mold filling. Ishikawa and Ohshima [9] designed a visualization mold in which a glass prism targeted the far end of the mold cavity to investigate the foaming behaviour of polypropylene (PP) blown with $\mathrm{CO}_{2}$ during mold opening. Ishikawa et al. [10] extended their study to compare the nucleation effectiveness of nitrogen $\left(\mathrm{N}_{2}\right)$ with that of $\mathrm{CO}_{2}$. Yamada et al. [11] observed a multilayer core structure in FIM experiments of PS blown with $\mathrm{N}_{2}$, and justified this phenomenon by the local cavity pressure.

Our study explains the development of a new visualization mold for online observation of bubble nucleation and growth dynamics in FIM, compatible with laboratory-scale and small size injection molding machines. Compared with previous designs, ours provides novel features such as visual accessibility to critical locations in the mold, i.e., near the gate, far from the gate, and the area in-between them, while measuring the pressures at the visualized locations. Another unique component of our design is the gate pressure transducer, which can be used, along with other pressure transducers across the mold cavity, to measure the pressure difference before and after the gate. In our previous study, it was demonstrated that the pressure distributions before the gate and along the mold cavity provide critical information about the foaming dynamics during filling [4]. Nevertheless, most bubble nucleation and growth phenomena had to be theorized based on the pressure data because of the lack of visualization data. On the other hand, the visualized foaming results in the literature could not be properly interpreted due to the lack of pressure distributions in the cavity. The earlier researchers used a pressure transducer either at the end of the cavity [7], near the end [9], or near the gate [11]. Although the measured pressure was used for the interpretation of their data, the local pressure and visualized data could not describe the entire foaming phenomena in the mold cavity as the pressure profile changes along the mold cavity.

Unlike most available designs, the selection of small transparent windows in our design minimizes the effective polymer/glass interface, simulating a more realistic FIM process in terms of the heat transfer and the rheological implications on the cavity surface (Figure 1). Also, it reduces the probability of any thermal shock, or mechanical damage under high packing pressures. The location of the viewing windows in the fixed plate, on the opposite side of the mold cavity, makes it possible to perform various experiments by simply changing the mold insert, some of which includes, but is not limited to, gasassisted FIM studies, shear/extension induced FIM, and the study of flow in various channels. Also, the mold can be utilized to investigate other FIM technologies such as gas-counter pressure (GCP) [12, 13] and mold opening (core back) [9, 10, 14, 15]. The designed mold can be utilized to further investigate the mechanisms of bubble nucleation/growth, interaction between bubbles and fillers [16, 17], the effect of formed crystals on foaming [18], weld-line studies [19], defects [20], and model verifications [21]. Since no commercial software can accurately describe the microcellular MuCell or structural FIM technologies, the use of the designed visualization mold will elucidate the details of the bubble nucleation mechanisms in FIM, and will provide reliable experimental data for model verification and software validation.

In this article, we demonstrate the dominant bubble nucleation mechanisms in low- and high-pressure FIM technologies by means of in-situ visualization. Polystyrene/ $\mathrm{CO}_{2}$ mixtures have been used as a case example.

\section{System development}

A detailed sketch of the designed visualization mold is shown in Figure 1. A prism-insert was designed and manufactured at which a right-angle glass prism was mounted to reflect the cavity images to a camera. The prism was a pure non-crystalline fused silica 7980 from Meller Optics Inc., with low refractive index variations, low birefringence values, and a low thermal expansion coefficient. The view surfaces of the prism were optically polished, and its hypotenuse was silver-coated in order to provide mirror action. The physical and optical properties of the prism are summarized in Table 1.

The reflective prism was precisely encased in a 4piece prism-insert (Figure 1a). An insert pocket was then cut into a block of P20 mold steel and the prism-insert was fixed inside the mold. Three round, fused silica windows were provided from BMV Optical and mounted in a metallic frame. To ensure that the pressure readings represented the local pressure of the visualized spot, each window was carefully located in front of each of the cavity pressure transducers on the opposite side of the cavity. To measure the pressure before the gate, a Dynisco pressure 


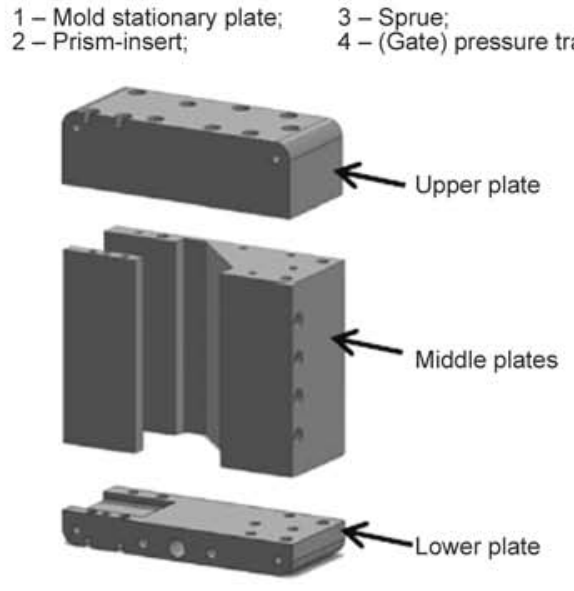

a)

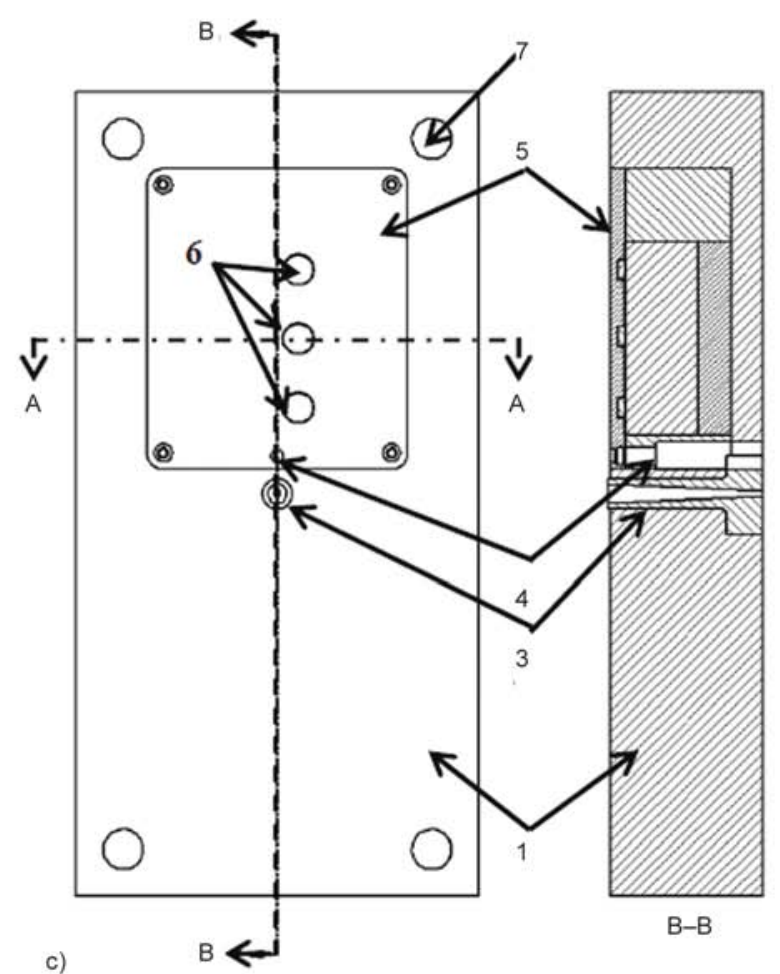

\section{5 - View window frame; 6 - View windows;

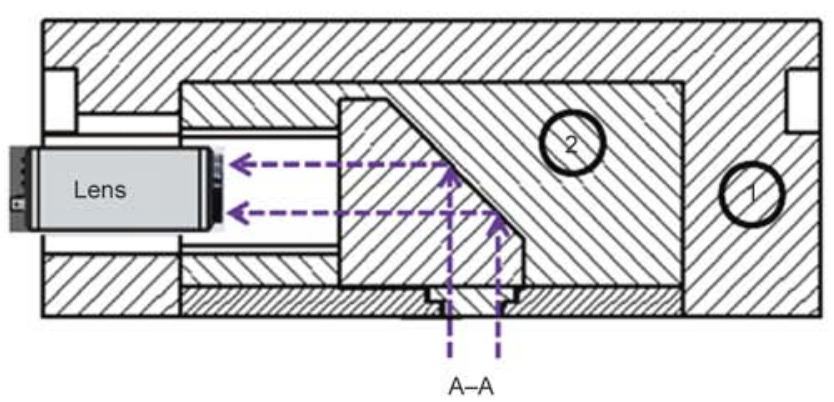

b)

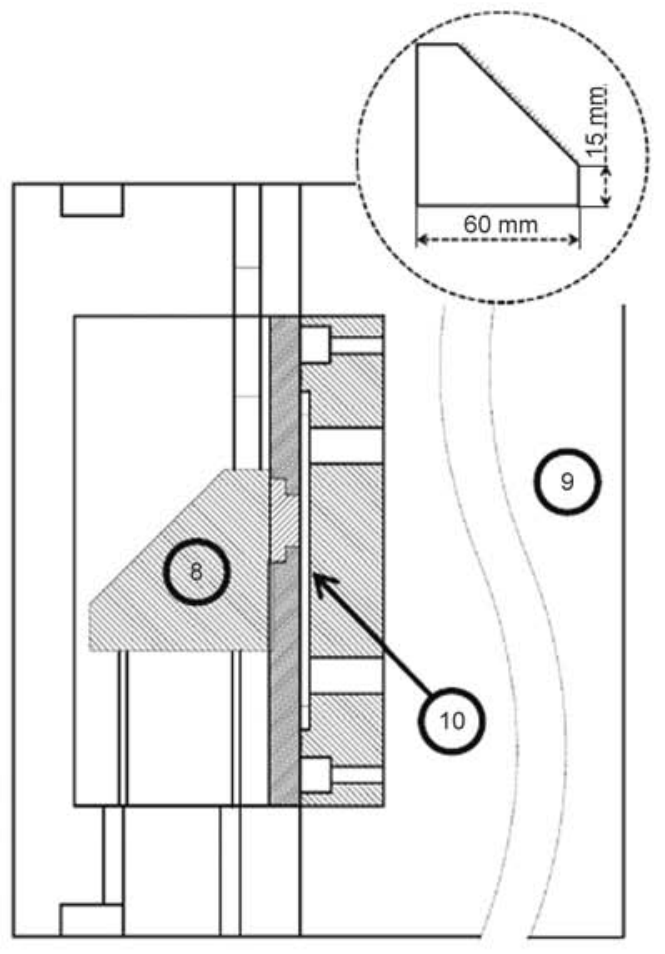

Figure 1. a) Prism-insert; b) top sectional view of the visualization mold stationary plate, the principle of the reflective prism, and the location of view windows; c) detailed design of the visualization mold stationary plate; d) top sectional view of the complete visualization mold

Table 1. Properties of fused silica

\begin{tabular}{|c|c|c|c|c|c|c|c|}
\hline Part & Grade & $\begin{array}{c}\text { Birefringence } \\
{[\mathrm{nm} / \mathrm{cm}]}\end{array}$ & $\begin{array}{c}\text { Shear Modulus }{ }^{*} \\
\text { [GPa] }\end{array}$ & $\begin{array}{c}\text { Bulk modulus* } \\
\text { [GPa]) }\end{array}$ & $\begin{array}{l}\text { Surface finish } \\
\text { [scratch/dig] }\end{array}$ & $\begin{array}{c}\text { Surface flatness } \\
\text { [wave] }\end{array}$ & $\begin{array}{l}\text { Density } \\
{\left[\mathrm{g} / \mathrm{cm}^{3}\right]}\end{array}$ \\
\hline Prism & 7980 Standard & $\leq 5$ & 31.0 & 35.9 & $40-10$ & 1 & 2.20 \\
\hline Window & $7980 \mathrm{KrF}$ & $\leq 1$ & 31.4 & 35.4 & $40-10$ & 1 & 2.20 \\
\hline
\end{tabular}

${ }^{*}$ Properties measured at $25^{\circ} \mathrm{C}$

transducer (Franklin, USA) was incorporated into the mold and its sensor surface was flush-mounted. The complete assembly of the visualization mold with a detailed view of the assembly section is shown in Figure 2.

\section{Materials and equipment}

A grade of PS from Americas Styrenics (The Woodlands, TX), MC3650, with MFI = $13.0 \mathrm{~g} / 10 \mathrm{~min}$, was blown using $\mathrm{CO}_{2}$ from Linde Gas Canada (Toronto, Canada). Nitrogen from Linde Gas Canada (Toronto, 


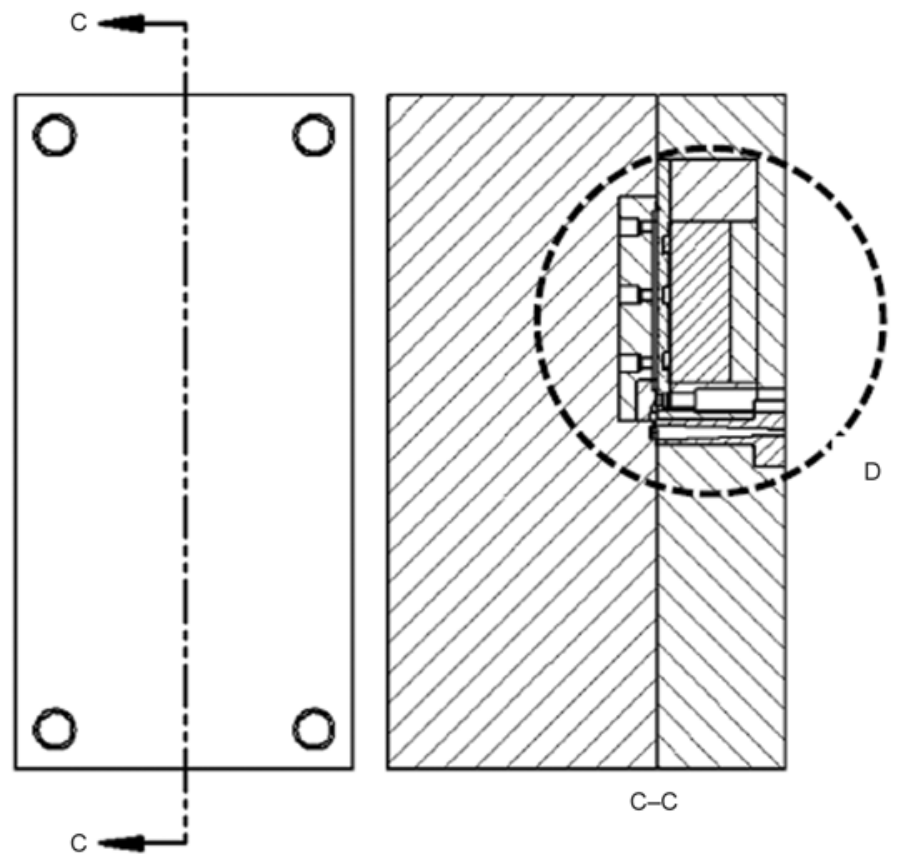

\footnotetext{
1 - Mold stationary plate (visualization plate); 2 - Mold moving plate; 3 - (Fan) gate; 4 - Mold cavity; 5 - Gate pressure transducer; 6 - Cavity pressure transducer (location A); 7 - Cavity pressure transducer (location $B$ ) 8 - Cavity pressure transducer (location C): ans

12 - Opening to camera
}

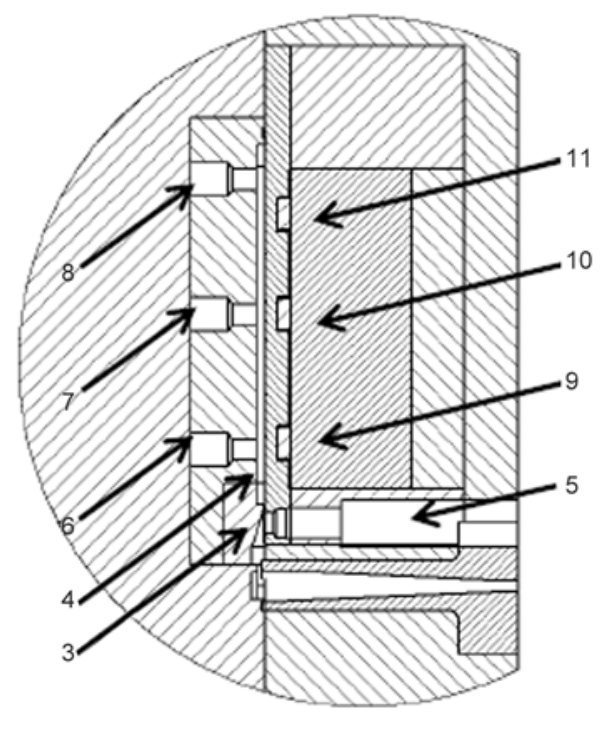

D

b)

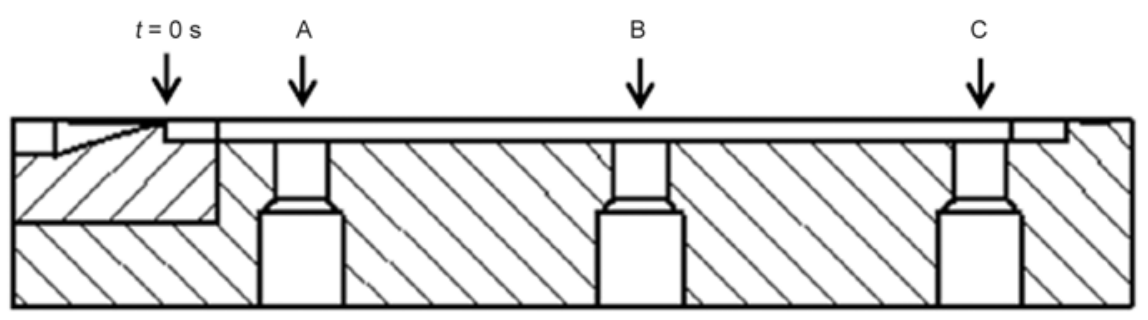

Figure 2. a) Visualization mold assembly and detailed location of the pressure transducers; b) gate and cavity cross section with identified locations ( $t=0 \mathrm{~s}$ at the entrance of the cavity)

Canada) was used as the GCP medium. A 50 ton Arburg ALLROUNDER 270C injection molding machine equipped with a Trexel MuCell SCF deliv- ery system was used to perform FIM experiments. A rectangular mold cavity with nominal dimensions of $135 \mathrm{~mm} \times 111 \mathrm{~mm} \times 3.2 \mathrm{~mm}$, fed by a fan gate, was 
Table 2. Processing parameters (in all experiments: $T_{\text {melt }}=230^{\circ} \mathrm{C} ; T_{\text {Mold }}=25-30^{\circ} \mathrm{C}$ ).

\begin{tabular}{|c|c|c|c|c|c|c|c|}
\hline Process & $\begin{array}{c}\text { Shot size } \\
{\left[\mathbf{c m}^{\mathbf{3}}\right]}\end{array}$ & $\begin{array}{c}\mathbf{C O}_{\mathbf{2}} \\
{[\mathbf{w} \mathbf{\%}]}\end{array}$ & $\begin{array}{c}\text { Packing pressure } \\
{[\mathbf{M P a}]}\end{array}$ & $\begin{array}{c}\text { Packing duration } \\
{[\mathbf{s}]}\end{array}$ & $\begin{array}{c}\text { Injection speed } \\
{\left[\mathbf{c m}^{\mathbf{3}} \mathbf{s}\right]}\end{array}$ & $\begin{array}{c}\mathbf{G C P} \\
{[\mathbf{M P a}]}\end{array}$ & $\begin{array}{c}\text { Barrel pressure } \\
{[\mathbf{M P a}]}\end{array}$ \\
\hline $\begin{array}{c}\text { Low-pressure FIM } \\
(\sim 20 \% \text { void fraction })\end{array}$ & 50 & 2 & 0 & None & 50 & None & 17 \\
\hline $\begin{array}{c}\text { Low-pressure FIM } \\
(\leq 5 \% \text { void fraction })\end{array}$ & 58 & 2 & 0 & None & 50 & None & 17 \\
\hline High-pressure FIM & 62 & 2 & 16 & 1 & 50 & None & 17 \\
\hline $\begin{array}{c}\text { Near full-shot FIM + } \\
\text { GCP }\end{array}$ & 60 & 1 & 0 & None & 50 & 3.5 & 17 \\
\hline
\end{tabular}

used to mold the samples. The imaging system consisted of a CV M10 camera from JAI and a magnifying lens from Navitar connected to a computer. To investigate the governing bubble nucleation mechanisms in FIM, three types of experiments were carried out, namely low-pressure FIM [4], high-pressure FIM [3], and (almost) full-shot FIM using GCP [3]. The processing parameters for the FIM experiments are listed in Table 2. This should be noted that three critical locations were identified for the visualization of the mold cavity, such that Location A was near the gate, Location $\mathrm{C}$ was far from the gate and close to the end of the mold cavity, and Location $\mathrm{B}$ was in between Locations A and C (Locations A to C correspond to each view window illustrated in Figure 1c). The visual observations demonstrated in this research were carried out at Location B, and the time reference (i.e. $t=0 \mathrm{~s}$ ) is set as the moment the melt/gas mixture enters the cavity (see Figure 2b).

\section{Results and discussion}

In FIM processing, a physical or chemical blowing agent (BA) is homogeneously mixed with the polymer melt, followed by a thermodynamic instability to induce bubble nucleation to the system [4]. The bubble nucleation mechanism and the final cellular structure are a strong function of the acquired ther- modynamic instability, via the pressure drop, which in turn depends on the type of the FIM process.

In low-pressure FIM, the mold cavity was partially filled with the melt/gas mixture [22]. In this scheme, the pressure of the melt/gas mixture dropped below the solubility pressure of the dissolved BA once it entered the mold cavity; therefore, a myriad of cells (i.e. gate-nucleated bubbles) nucleate at the gate. Figure 3a schematically shows the cell nucleation and free-expansion growth in low-pressure FIM. As illustrated, gate-nucleated bubbles grow, get sheared and elongated, and coalesce during their travel along the mold cavity. Figure $3 \mathrm{~b}$ shows the successive snapshots of the cavity visualization for a low-pressure FIM with $20 \%$ void fraction. Because of the large void fraction, the cavity pressure remained below the solubility pressure of the BA; hence a large number of cells were nucleated at the gate under a fast pressure drop rate, and the (foggy) melt front was associated with fast cell nucleation and gas escape. In this case, the nucleated bubbles could not be visually detected. In order to visualize the behaviour of bubbles, we increased the shot size (i.e. smaller void fraction) such that the increased cavity pressure suppressed the cell nucleation at the gate to a large extent. Therefore, a smaller number of cells were induced during filling, and a clear image
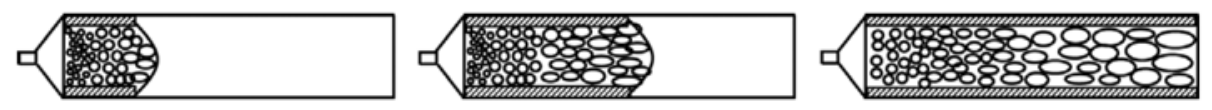

a)

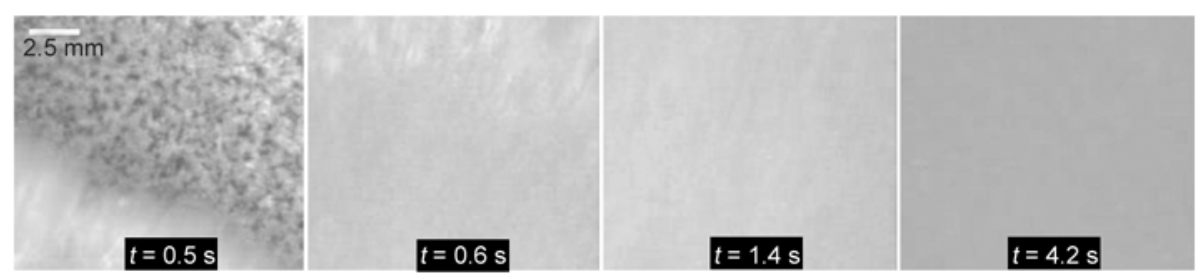

b)

Figure 3. a) Schematic of low-pressure FIM (formation and growth of gate-nucleated bubbles, which get sheared and coalesced during mold filling and free expansion; the hatched area shows the formed skin layer); b) successive snapshots for low-pressure FIM experiments of PS-2\% CO $\mathrm{CO}_{2}$ with $20 \%$ void fraction. (Injection Speed $=50 \mathrm{~cm}^{3} \cdot \mathrm{s}^{-1}$; $T_{\text {melt }}=230^{\circ} \mathrm{C}$; Visualization location $=\mathrm{B}$. The time was set to zero at the moment when the melt entered the mold cavity.) 

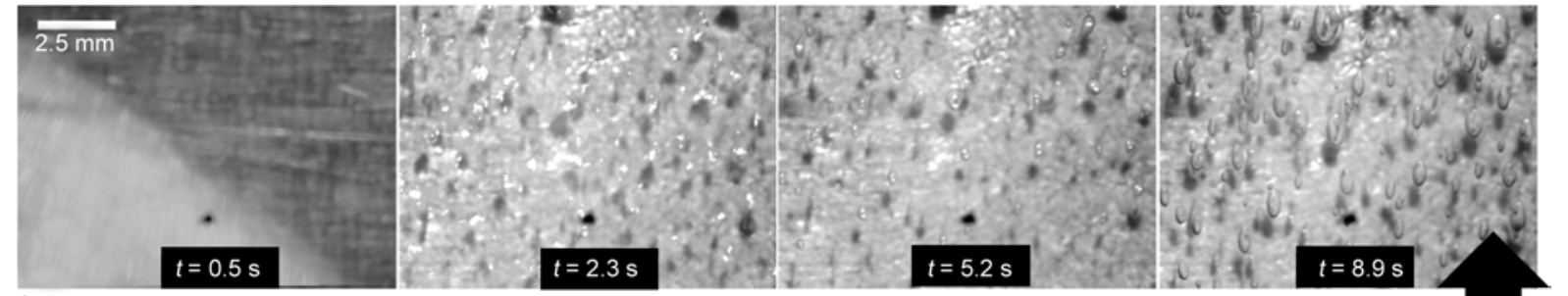

a)
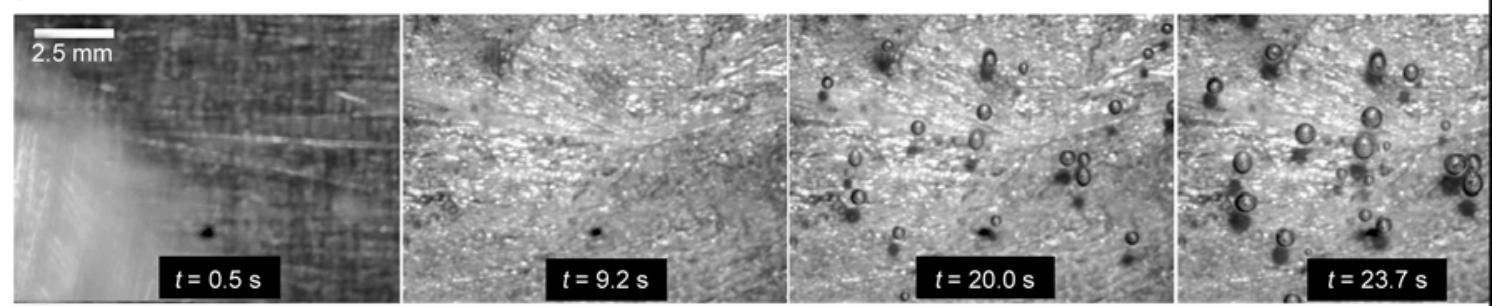

b)
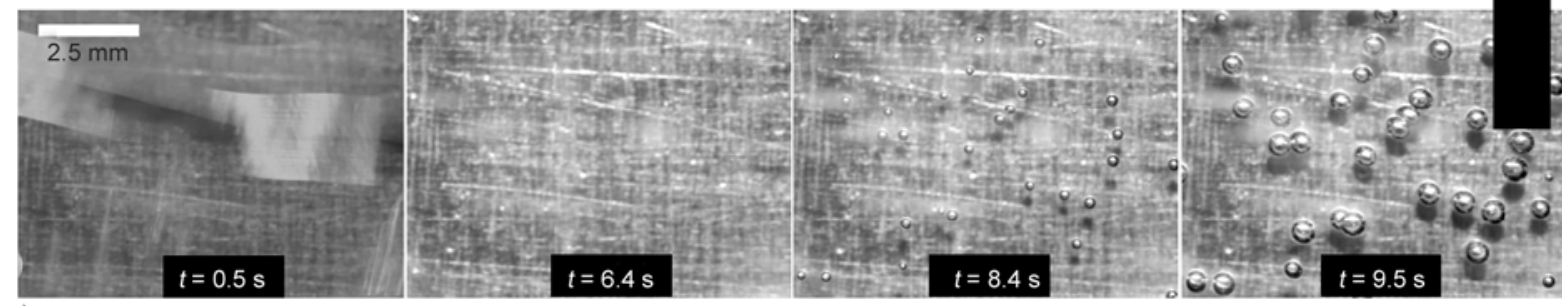

c)

Figure 4. Mechanism of bubble nucleation in FIM: a) Low-pressure FIM, $\mathrm{CO}_{2}=2 \%$; void fraction $\leq 5 \%$; b) high-pressure FIM, $\mathrm{CO}_{2}=2 \%$, pack pressure $=16 \mathrm{MPa}$, packing time $=1 \mathrm{~s} ; \mathrm{c}$ ) foam injection molding using $\mathrm{GCP}, \mathrm{CO}_{2}=1 \%$, GCP removal time $=7 \mathrm{~s}$ (Injection speed $=50 \mathrm{~cm}^{3} \cdot \mathrm{s}^{-1} ; T_{\text {melt }}=230^{\circ} \mathrm{C}$; Visualization location $=\mathrm{B}$. The time was set to zero at the moment when the melt entered the mold cavity.)

was obtained, as shown in Figure 4a. The bubble nucleation occurred very quickly as a result of the pressure drop obtained over the gate (where the time was set to zero). As the melt flowed along the cavity, the gate-nucleated bubbles grew as a sensitive function of the mold pressure by the diffusion of the remaining gas molecules into the nucleated bubbles, as shown for $t=2.3$ to $8.9 \mathrm{~s}$ in Figure $4 \mathrm{a}$. Because of the pressure gradient across the mold cavity and bubble coalescence, considerable inhomogeneity in the foam morphology is typically developed at different locations of the mold.

In high-pressure FIM, on the other hand, a full shot was used to completely fill out the mold cavity. As in the case of low-pressure FIM, foaming occurred upon the entry of the melt/gas mixture into the mold cavity. However, all the gate-nucleated bubbles are to re-dissolve into the melt under the cavity pressure in this method. If the cavity pressure does not suffice for dissolution of gate-nucleated bubbles, then the melt packing pressure can be continuously applied. The pressure drop, responsible for bubble nucleation, is then attainable during melt solidification and shrinkage. As shown in Figure 4b, foaming started upon the entry of the melt/gas mixture into the cavity, and the melt front advancement was associated with bubble nucleation, foaming, and gasescape. However, the gate-nucleated bubbles disappeared under the cavity pressure and new bubbles eventually nucleated, after about 9 seconds, during solidification. Therefore, the main difference between the nucleation mechanism in low-pressure and high-pressure FIM schemes was the source of the pressure drop, which induced bubble nucleation.

In order to increase the surface quality and structural homogeneity of FIM parts, the FIM process was performed using GCP $[12,13]$. In this method, the mold cavity was charged with GCP, higher than the solubility pressure of the dissolved BA, prior to the filling step. This high-pressure gas was then exhausted as the injection proceeded. Figure $4 \mathrm{c}$ illustrates successive snapshots from visualization results of FIM experiments using GCP. As demonstrated, the GCP prevented foaming and gas-scape, evidenced by a smooth and transparent melt front, and postponed the bubble nucleation moment till the end of the filling stage. Once the GCP was removed, bubble nucleation occurred.

The cavity pressure profiles, at Locations A and B, corresponding to the aforementioned experiments 

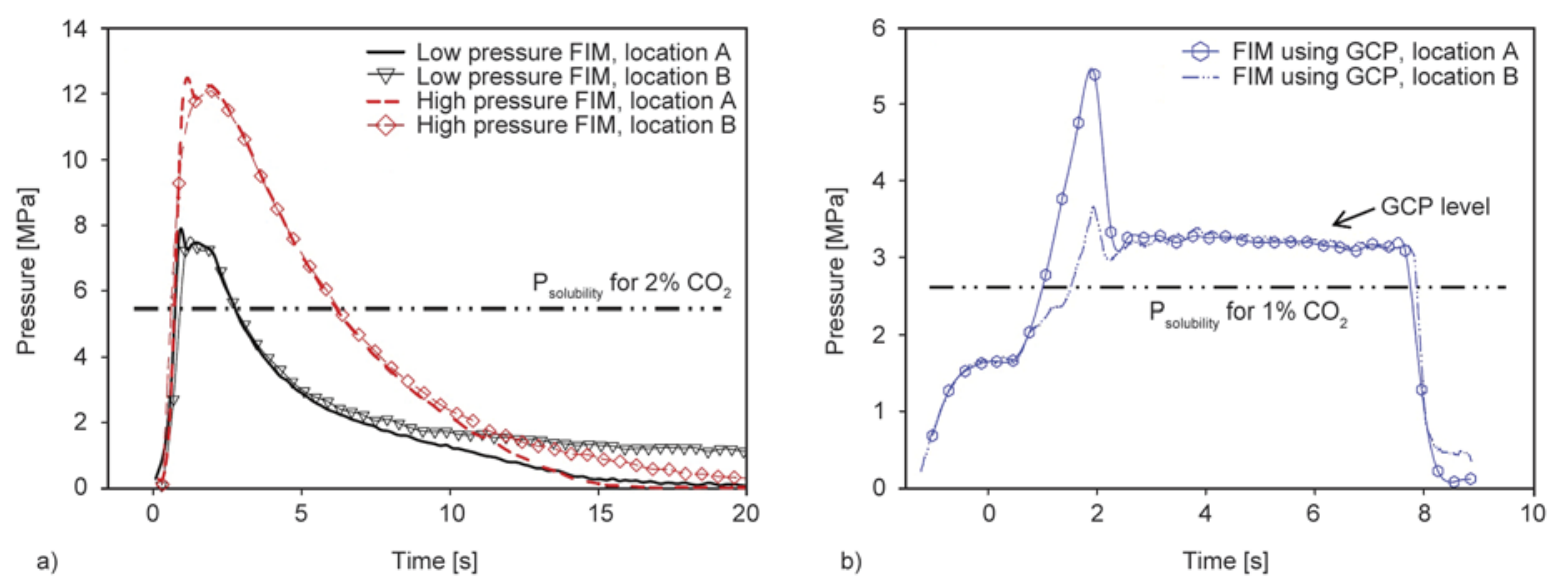

Figure 5. Pressure profiles in FIM experiments at $50 \mathrm{~cm}^{3} \cdot \mathrm{s}^{-1}$ a) low- and high-pressure FIM; b) FIM+GCP (The time reference is the moment of the melt entry into the mold cavity.)

are shown in Figure 5. The cavity pressures in highpressure FIM were higher than those in low-pressure FIM, due to the application of melt packing. Further, while a discrepancy was observed in pressure-decay profiles recorded at Locations A and B in low-pressure FIM, the pressure profiles almost coincided in the cases of high-pressure FIM and FIM experiments using GCP. Compared with the high-pressure case, a greater discrepancy in the pressure-decay profiles recorded at Locations A and $\mathrm{B}$ of low-pressure experiments indicated on bigger bubbles at Location B and a larger structural heterogeneity. The study of pressure profiles in experiments using GCP revealed that a very rapid pressure drop, but similar, was obtained at both Locations A and B upon the GCP release, enhancing the bubble nucleation rate and improving the structural uniformity.

\section{Conclusions}

An innovative visualization mold was successfully designed and used to investigate bubble nucleation and growth in foam injection molding. Visualization results revealed that the prevailing nucleation mechanisms in low-pressure foam injection molding is the one occurring as a result of the pressure drop obtained at the gate. In high-pressure foam injection molding, in contrast, the gate-nucleated bubbles disappeared under the high pressure of the mold cavity using melt packing, and the nucleation of new bubbles, happening during melt solidification and shrinkage, governed the ultimate cellular structure. The pressure profiles recorded at visualized spots indicated on a higher cavity pressure, required for the dissolution of gate-nucleated bubbles in high- pressure foam injection molding. By the application of gas-counter pressure, bubble nucleation was prevented till the end of the mold filling, and initiated upon the gas-counter pressure removal. By combining the information from in-situ visualization and cavity pressure, proper processing conditions can be effectively derived for each processing scheme.

\section{Acknowledgements}

This work was supported by the Natural Science and Engineering Research Council of Canada (NSERC 154279-2010). The authors are grateful to the Consortium of Cellular and Micro-Cellular Plastics (CCMCP) for their financial support. The polystyrene used in this research was provided by Americas Styrenics, TX, United States. Special thanks to Ryan Mendell, Machine Shop Manager, and Gordon Boudreau and Jeff Sansome, Machine Shop specialists, in the Department of Mechanical and Industrial Engineering of the University of Toronto, for their professional advice and constant support.

\section{References}

[1] Ameli A., Jung P. U., Park C. B.: Electrical properties and electromagnetic interference shielding effectiveness of polypropylene/carbon fiber composite foams. Carbon, 60, 379-391 (2013). DOI: $10.1016 /$ j.carbon.2013.04.050

[2] Ameli A., Wang S., Kazemi Y., Park C. B., Pötschke P.: A facile method to increase the charge storage capability of polymer nanocomposites. Nano Energy, 15, 5465 (2015).

DOI: 10.1016/j.nanoen.2015.04.004

[3] Ameli A., Jahani D., Nofar M., Jung P. U., Park C. B.: Development of high void fraction polylactide composite foams using injection molding: Mechanical and thermal insulation properties. Composites Science and Technology, 90, 88-95 (2014).

DOI: $10.1016 /$ j.compscitech.2013.10.019 
[4] Lee J. W. S., Wang J., Yoon J. D., Park C. B.: Strategies to achieve a uniform cell structure with a high void fraction in advanced structural foam molding. Industrial and Engineering Chemistry Research, 47, 94579464 (2009).

DOI: $10.1021 / \mathrm{ie} 0707016$

[5] Arefmanesh A., Advani S. G., Michaelides E. E.: A numerical study of bubble growth during low pressure structural foam molding process. Polymer Engineering and Science, 30, 1330-1337 (1990).

DOI: $10.1002 /$ pen.760302011

[6] Ramesh N. S., Rasmussen D. H., Campbell G. A.: Numerical and experimental studies of bubble growth during the microcellular foaming process. Polymer Engineering and Science, 31, 1657-1664 (1991). DOI: $10.1002 /$ pen.760312305

[7] Villamizar C. A., Han C. D.: Studies on structural foam processing II. Bubble dynamics in foam injection molding. Polymer Engineering and Science, 18, 699-710 (1978).

DOI: $10.1002 /$ pen.760180905

[8] Mahmoodi M., Behravesh A. H., Rezavand S. A. M., Pashaei A.: Visualization of bubble dynamics in foam injection molding. Journal of Applied Polymer Science, 116, 3346-3355 (2010).

DOI: 10.1002/app.31839

[9] Ishikawa T., Ohshima M.: Visual observation and numerical studies of polymer foaming behavior of polypropylene/carbon dioxide system in a core-back injection molding process. Polymer Engineering and Science, 51, 1617-1625 (2011). DOI: $10.1002 /$ pen.21945

[10] Ishikawa T., Taki K., Ohshima M.: Visual observation and numerical studies of $\mathrm{N}_{2}$ vs. $\mathrm{CO}_{2}$ foaming behavior in core-back foam injection molding. Polymer Engineering and Science, 52, 875-883 (2012).

DOI: $10.1002 /$ pen.22154

[11] Yamada T., Murata Y., Yokoi H.: Visualization analysis of a multilayer foam development process in microcellular injection molding. International Polymer Processing, 27, 299-309 (2012).

DOI: $10.3139 / 217.2443$

[12] Chen S-C., Liao W-H., Chien R-D.: Structure and mechanical properties of polystyrene foams made through microcellular injection molding via control mechanisms of gas counter pressure and mold temperature. International Communications in Heat and Mass Transfer, 39, 1125-1131 (2012).

DOI: 10.1016/j.icheatmasstransfer.2012.06.015
[13] Chen S-C., Hsu P-S., Hwang S-S.: The effects of gas counter pressure and mold temperature variation on the surface quality and morphology of the microcellular polystyrene foams. Journal of Applied Polymer Science, 127, 4769-4776 (2013).

DOI: 10.1002/app.37994

[14] Spörrer A. N. J., Altstädt V.: Controlling morphology of injection molded structural foams by mold design and processing parameters. Journal of Cellular Plastics, 43, 313-330 (2007). DOI: $10.1177 / 0021955 X 07079043$

[15] Stumpf M., Spörrer A., Schmidt H. W., Altstädt V.: Influence of supramolecular additives on foam morphology of injection-molded i-PP. Journal of Cellular Plastics, 47, 519-534 (2011). DOI: $10.1177 / 0021955 X 11408769$

[16] Ameli A., Nofar M., Wang S., Park C. B.: Lightweight polypropylene/stainless-steel fiber composite foams with low percolation for efficient electromagnetic interference shielding. ACS Applied Materials and Interfaces, 6, 11091-11100 (2014).

DOI: $10.1021 / \mathrm{am} 500445 \mathrm{~g}$

[17] Ameli A., Nofar M., Park C. B., Pötschke P., Rizvi G.: Polypropylene/carbon nanotube nano/microcellular structures with high dielectric permittivity, low dielectric loss, and low percolation threshold. Carbon, 71, 206-217 (2014). DOI: $10.1016 /$ j.carbon.2014.01.031

[18] Nofar M., Park C. B.: Poly (lactic acid) foaming. Progress in Polymer Science, 39, 1721-1741 (2014). DOI: 10.1016/j.progpolymsci.2014.04.001

[19] Fathi S., Behravesh A. H.: Visualization analysis of flow behavior during weld-line formation in injection molding process. Polymer-Plastics Technology and Engineering, 47, 666-672 (2008). DOI: $10.1080 / 03602550802129536$

[20] Yokoi H., Masuda N., Mitsuhata H.: Visualization analysis of flow front behavior during filling process of injection mold cavity by two-axis tracking system. Journal of Materials Processing Technology, 130-131, 328-333 (2002). DOI: 10.1016/S0924-0136(02)00742-2

[21] Leung S. N., Park C. B., Xu D., Li H., Fenton R. G.: Computer simulation of bubble-growth phenomena in foaming. Industrial and Engineering Chemistry Research, 45, 7823-7831 (2006). DOI: $10.1021 / \mathrm{ie} 060295 \mathrm{a}$

[22] Ameli A., Nofar M., Jahani D., Rizvi G., Park C. B.: Development of high void fraction polylactide composite foams using injection molding: Crystallization and foaming behaviors. Chemical Engineering Journal, 262, 78-87 (2015).

DOI: $10.1016 /$ j.cej.2014.09.087 